\title{
Dermatology
}

Dermatology 2010;220:46-48

DOI: $10.1159 / 000258674$

\section{Increased Serum Levels of Growth-Related Oncogene- $\alpha$ in Patients with Generalized Pustular Psoriasis}

\section{Yasunobu Kato, Toshiyuki Yamamoto}

Department of Dermatology, Fukushima Medical University, Fukushima, Japan

\section{Key Words}

Pustular psoriasis $\cdot$ Zumbusch $\cdot$ Growth-related oncogene- $\alpha \cdot$ Chemokine

Generalized pustular psoriasis (GPP) is a rare systemic disease characterized by widespread, superficial sterile pustules over the trunk, which rapidly develop into erythroderma. Histologically, GPP demonstrates subcorneal abscess, acanthosis and cellular infiltrates in the papillary dermis. Neutrophils are supposed to be attracted by some chemotactic factors into the epidermis [1]; however, the mechanism of pustular formation in GPP is still unclear.

Growth-related oncogene- $\alpha(\mathrm{GRO}-\alpha) / \mathrm{CXCL1}$ is an ELR-positive CXC chemokine that recruits and activates neutrophils. GRO- $\alpha$ is also chemotactic for basophils. It is produced by various cell types including macrophages, neutrophils, epithelial cells, endothelial cells and fibroblasts. Until now, increased GRO- $\alpha$ levels have been reported in association with several disorders such as rheumatoid arthritis [2], psoriasis [3] and systemic sclerosis [4]. In this study, we examined serum levels of GRO- $\alpha$ in patients with GPP and evaluated the relationship to clinical severities in a patient with Zumbusch-type GPP.

Sera were obtained from 5 patients wit GPP ( 3 males and $2 \mathrm{fe}$ males) ranging from 27 to 84 years old (mean $=47.6)$. Serum levels of GRO- $\alpha$ were measured with specific enzyme-linked immunosorbent assay kits (Quantikine, R\&D Systems, Minneapolis, Minn., USA). As controls, 15 patients with psoriasis vulgaris (PV) (10 males and 5 females with a mean age of 50.3 years, PASI score $<10$ in all patients), 10 patients with palmoplantar pustulosis (PPP) ( 3 males and 7 females with a mean age of 42.5 years) and 19 healthy controls consisting of 10 males and 9 females (mean age $\pm \mathrm{SD}=44.0 \pm 16.8$ years) were also examined.

The GPP patients had higher serum GRO- $\alpha$ levels (363.5 \pm $148.2 \mathrm{pg} / \mathrm{ml})$ than the controls $(101.8 \pm 31.7 \mathrm{pg} / \mathrm{ml} ; \mathrm{p}<0.01$, Mann-Whitney U test), PV patients $(157.3 \pm 78.3 \mathrm{pg} / \mathrm{ml} ; \mathrm{p}<0.05)$ and PPP patients $(116.0 \pm 47.1 \mathrm{pg} / \mathrm{ml} ; \mathrm{p}<0.01)$ (fig. 1$)$. Among the 5 patients with GPP, the serum GRO- $\alpha$ levels of 3 patients

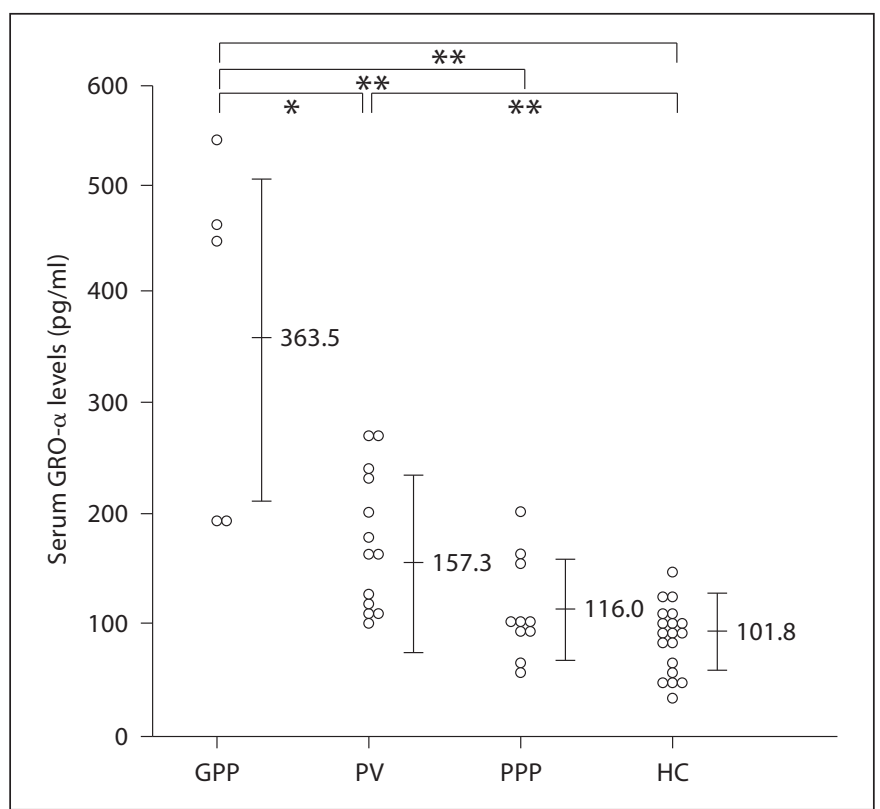

Fig. 1. Serum levels of GRO- $\alpha$ in patients with GPP $(n=5), P V$ $(\mathrm{n}=15), \operatorname{PPP}(\mathrm{n}=10)$ and healthy controls $(\mathrm{HC}, \mathrm{n}=19) .{ }^{*} \mathrm{p}<0.05$, ** $\mathrm{p}<0.01$.

showed extremely high levels, and they clinically exhibited acute worsening with a number of pustules developing into erythroderma. By contrast, the levels of the remaining 2 patients were as high as those of the PV patients. These patients were well-controlled and in inactive states. Next, we assessed the relationship between serum GRO- $\alpha$ levels and clinical severities in a 33-yearold woman with Zumbusch-type GPP. As is shown in figure 2, the serum GRO- $\alpha$ level was extremely high at the time of acute deterioration with some pustular formation $(447.2 \mathrm{pg} / \mathrm{ml})$, which was decreased following systemic therapies with corticosteroids (153.8 $\mathrm{pg} / \mathrm{ml})$. Thereafter, serum GRO- $\alpha$ levels again increased at the time of relapse of pustulation $(310.7 \mathrm{pg} / \mathrm{ml})$. Also, the titers of GRO- $\alpha$ were correlated with CRP levels. The correlation between the serum GRO- $\alpha$ levels and the number of circulating leukocytes or neutrophils was uncertain because this patient had been treated with systemic corticosteroids. However, the percentage of neutrophils shifted relatively in parallel.

GPP is histologically characterized by the formation of pustules and demonstrates numerous superficial pustules which are macroscopically recognized. Collections of polymorphonuclear leukocytes migrate from the dermal papillae into the dermis, de-

\section{KARGER}

(c) 2009 S. Karger AG, Basel

Fax +41 613061234 E-Mail karger@karger.ch www.karger.com 


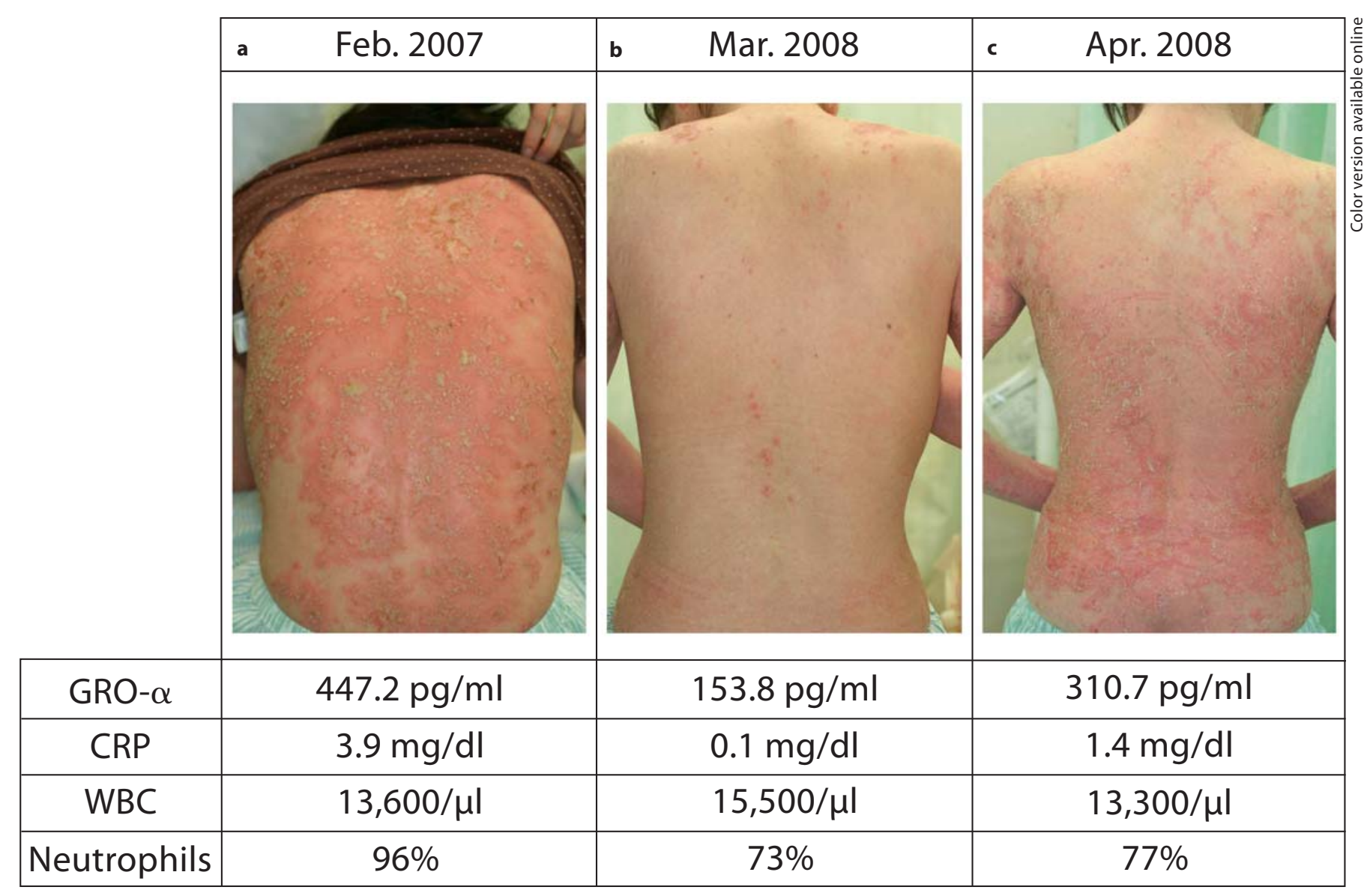

Fig. 2. Shift of serum GRO- $\alpha$ levels in tandem with the acute exacerbation (a), remission by systemic corticosteroids (b) and relapse (c) of GPP. CRP $=$ C-reactive protein; WBC $=$ white blood cells.

veloping into microabscess. Selective accumulation of neutrophils could be supposed to be caused by the local generation of neutrophil-specific chemoattractants, i.e. IL-8, GRO- $\alpha$ and C5a, which leads to the hypothesis that lesional keratinocytes play an important role in eliciting neutrophilic inflammatory response mechanisms. IL- 8 and GRO- $\alpha$ are potent chemoattractants and activators for neutrophils. IL- 8 has been detected in several disorders characterized by neutrophil activation such as pustular psoriasis, rheumatoid arthritis and Behcet's disease. Circulating levels and expression of IL- 8 have been shown to be increased in patients with GPP $[5,6]$. In this study, we examined the serum concentrations of GRO- $\alpha$ in 5 patients with GPP. The results showed that patients with GPP had significantly higher serum GRO- $\alpha$ levels than healthy controls. Also, the serum GRO- $\alpha$ levels in patients with GPP were significantly higher than those of patients with either PV or PPP.

Moreover, the investigation using sera from a single individual revealed that GRO- $\alpha$ levels were significantly elevated in tandem with the worsening of GPP presenting some pustula formation and general symptoms, which were markedly decreased after systemic therapy and again increased with relapse. These data suggest that GRO- $\alpha$ strongly reflects disease activity, but a longi- tudinal study in a higher number of patients will provide more information about the role of GRO- $\alpha$ in GPP. The proinflammatory cytokines including IL-6, tumor necrosis factor- $\alpha$ (TNF- $\alpha$ ) and IL- 8 are elevated in GPP $[6,7]$. These cytokines may have a regulatory role in neutrophil functions. Also, TNF- $\alpha$ and IL-1 $\beta$ stimulate GRO- $\alpha$ gene expression, which may be related to enhanced levels of GRO- $\alpha$ in patients with GPP. Recent reports have shown that blockade of TNF- $\alpha$ is effective in the treatment of pustular psoriasis [8-10] and acrodermatitis continua of Hallopeau [11]. In correlation with the rapid improvement of GPP by antiTNF- $\alpha$ therapy, various leukocyte populations infiltrating into the skin were significantly decreased [10]. Neutralization of local TNF production by anti-TNF antibodies interferes at a central pathogenic step, presumably by blocking trafficking of leukocytes into the skin [10]. Benoit et al. [8] reported that GRO- $\alpha$ mRNA is strongly expressed in the upper dermis around spongiform abscess of pustular psoriasis, which became undetectable after successful treatment with anti-TNF- $\alpha$ therapy. We speculate that the major source of elevated GRO- $\alpha$ concentration in the sera is activated circulating monocytes in patients with active GPP, but further studies are necessary. 
In conclusion, our studies demonstrate that serum GRO- $\alpha$ levels are increased in sera of patients with GPP and correlate with clinical severities forming a number of pustules. Unfortunately we could not examine the in situ expression of GRO- $\alpha$ in the lesional skin because frozen sections were not available, and thus we are currently planning to examine GRO- $\alpha$ expression in GPP. Although the precise function of GRO- $\alpha$ in GPP is still unknown, GRO- $\alpha$ may recruit and activate neutrophils in the lesional skin and possibly contribute to disease deterioration in GPP. Our results also indicate that GRO- $\alpha$ may be a reliable marker for the activity and severity of GPP.

\section{References}

1 Terui T, Ozawa M, Tagami H: Role of neutrophils in induction of acute inflammation in T-cell-mediated immune dermatosis, psoriasis: a neutrophil-associated inflammation-boosting loop. Exp Dermatol 2000;9: $1-10$.

- 2 Koch AE, Kunkel SL, Shah MR, Hosaka S, Halloran MM, Haines GK, Burdick MD, Pope RM, Strieter RM: Growth-related gene product $\alpha$ : a chemotactic cytokine for neutrophils in rheumatoid arthritis. J Immunol 1995; 155:3660-3666.

- 3 Kojima T, Cromie MA, Fisher GJ, Voorhees JJ, Elder JT: GRO- $\alpha$ mRNA is selectively overexpressed in psoriatic epidermis and is reduced by cyclosporine A in vivo, but not in cultured keratinocytes. J Invest Dermatol 1993;101:767-772.

4 Furuse S, Fujii H, Kaburagi Y, Fujimoto M, Hasegawa M, Takehara K, Sato S: Serum concentrations of the CXC chemokines interleukin 8 and growth-regulated oncogene- $\alpha$ are elevated in patients with systemic sclerosis. J Rheumatol 2003;30:1524-1528.
5 Duan H, Koga T, Kohda F, Hara H, Urabe K, Furue M: Interleukin-8positive neutrophils in psoriasis. J Dermatol Sci 2001;26:119-124.

-6 Kamarashev J, Lor P, Forster A, Heinzerling L, Burg G, Nestle FO: Generalized pustular psoriasis induced by cyclosporine A withdrawal responding to the tumor necrosis factor inhibitor etanercept. Dermatology 2002;205:213-216.

7 Seishima M, Takemura M, Saito K, Kitajima Y: Increased serum soluble Fas, tumor necrosis factor $\alpha$ and interleukin 6 concentrations in generalized pustular psoriasis. Dermatology 1998;196:371-372.

-8 Benoit S, Toksoy A, Bröcker EB, Gillitzer R, Goebeler M: Treatment of recalcitrant pustular psoriasis with infliximab: effective reduction of chemokine expression. Br J Dermatol 2004;150:1009-1012.

-9 Esposito M, Mazzotta A, Casciello C, Chimenti S: Etanercept at different dosages in the treatment of generalized pustular psoriasis: a case series. Dermatology 2008;216:355-360.

10 Yawalkar N, Hunger RE: Successful treatment of recalcitrant palmoplantar pustular psoriasis with sequential use of infliximab and adalimumab. Dermatology 2009;218:79-83.

-11 Thielen AM, Barde C, Marazza G, Saurat JH: Long-term control with etanercept (Enbrel) of a severe acrodermatitis continua of Hallopeau refractory to infliximab (Remicade). Dermatology 2008;217:137-139.

\section{Yasunobu Kato}

Department of Dermatology

Fukushima Medical University

Hikarigaoka 1, Fukushima, 960-1295 (Japan)

Tel. +81 24547 1309, Fax +81245485412

E-Mail ykato@fmu.ac.jp 